OPEN ACCESS

Edited by:

Rita Balice-Gordon, Sanofi, USA

Reviewed by: De-Lai Qiu,

Yanbian University, China Chong Shen,

University of Colorado Boulder, USA

*Correspondence:

Sergei M. Antonov antonov452002@yahoo.com

Received: 21 July 2016 Accepted: 07 October 2016 Published: 01 November 2016

Citation:

Sibarov DA, Abushik PA, Giniatullin $R$ and Antonov SM (2016)

GluN2A Subunit-Containing NMDA Receptors Are the Preferential Neuronal Targets of Homocysteine. Front. Cell. Neurosci. 10:246. doi: 10.3389/fncel.2016.00246

\section{GluN2A Subunit-Containing NMDA Receptors Are the Preferential Neuronal Targets of Homocysteine}

\author{
Dmitry A. Sibarov ${ }^{1}$, Polina A. Abushik ${ }^{1}$, Rashid Giniatullin ${ }^{2,3}$ and Sergei M. Antonov ${ }^{1 *}$ \\ ${ }^{1}$ Laboratory of Comparative Neurophysiology, Sechenov Institute of Evolutionary Physiology and Biochemistry of the \\ Russian Academy of Sciences, Saint-Petersburg, Russia, ${ }^{2}$ Department of Neurobiology, University of Eastern Finland, \\ Kuopio, Finland, ${ }^{3}$ Laboratory of Neurobiology, Kazan Federal University, Kazan, Russia
}

Homocysteine $(\mathrm{HCY})$ is an endogenous redox active amino acid, best known as contributor to various neurodegenerative disorders. Although it is known that HCY can activate NMDA receptors (NMDARs), the mechanisms of its action on receptors composed of different NMDA receptor subunits remains almost unknown. In this study, using imaging and patch clamp technique in cultured cortical neurons and heterologous expression in HEK293T cells we tested the agonist activity of HCY on NMDARs composed of GluN1 and GluN2A subunits (GluN1/2A receptors) and GluN1 and GluN2B subunits (GluN1/2B receptors). We demonstrate that the time courses of $\mathrm{Ca}^{2+}$ transients and membrane currents activated by HCY and NMDA in cortical neurons are drastically different. Application of HCY to cortical neurons induced responses, which in contrast to currents induced by NMDA (both in the presence of glycine) considerably decreased to steady state of small amplitude. In contrast to NMDA, HCYactivated currents at steady state were resistant to the selective GluN2B subunit inhibitor ifenprodil. In calcium-free external solution the decrease of NMDA evoked currents was abolished, suggesting the $\mathrm{Ca}^{2+}$-dependent NMDAR desensitization. Under these conditions HCY evoked currents still declined almost to the baseline suggesting $\mathrm{Ca}^{2+}$. independent desensitization. In HEK293T cells HCY activated NMDARs of GluN1/2A and GluN1/2B subunit compositions with $\mathrm{EC}_{50} \mathrm{~s}$ of $9.7 \pm 1.8$ and $61.8 \pm 8.9 \mu \mathrm{M}$, respectively. Recombinant GluN1/2A receptors, however, did not desensitize by HCY, whereas GluN1/2B receptors were almost fully desensitized by HCY. Thus, HCY is a high affinity agonist of NMDARs preferring the GluN1/2A subunit composition. Our data suggest that HCY induced native NMDAR currents in neurons are mainly mediated by the "synaptic type" GluN1/2A NMDARs. This implies that in hyperhomocysteinemia, a disorder with enlarged level of $\mathrm{HCY}$ in plasma, $\mathrm{HCY}$ may persistently contribute to post-synaptic responses mediated by GluN2A-containing NMDA receptors. On the other hand, HCY toxicity may be limited by desensitization typical for HCY-induced activation of GluN2B-containing extrasynaptic receptors. Our findings, therefore, provide an evidence for the physiological relevance of endogenous $\mathrm{HCY}$, which may represent an effective endogenous modulator of the central excitatory neurotransmission.

Keywords: homocysteine, glutamate, NMDA receptor, desensitization, neurons, primary culture, GluN2A, GluN2B 


\section{INTRODUCTION}

L-Homocysteine [2-amino-4-sulfanylbutanoic acid (HCY)] is an endogenous sulfur-containing amino acid involved in synthesis of methionine and cysteine. The normal HCY level in plasma is generally below $16 \mu \mathrm{M}$ (Shi et al., 2003). However, a deficit of folic acid and vitamins B or the C677T polymorphism of the $5^{\prime}-10^{\prime}$-methylenetetrahydrofolate reductase gene (a substitution of cytosine for thymine at position 677, C677T) can cause an elevation of HCY level (a condition known as hyperhomocysteinemia, Kowa et al., 2000). High level of HCY have been proposed to contribute to a variety of cardiovascular and neurodegenerative disorders, such as Alzheimer's and Parkinson's disease (Kuhn et al., 2001; Kruman et al., 2002; Sachdev, 2005) as well as amyotrophic lateral sclerosis (Zoccolella et al., 2010). Recent data implicate the C677T polymorphism in the pathogenesis of migraine with aura (Moschiano et al., 2008; Lea et al., 2009; Oterino et al., 2010). We previously showed that the high level of HCY led to the neuronal death through activation of NMDA receptors (NMDARs) and mGluR5 (Abushik et al., 2014).

Several studies reported that HCY (Lipton et al., 1997; Ganapathy et al., 2011; Bolton et al., 2013), as well as its derivative, homocysteic acid, studied earlier (Provini et al., 1991; Kilić et al., 1992) is an agonist operating via the glutamate binding sites of the NMDARs. In addition, HCY at relatively high concentrations (above $1 \mathrm{mM} \mathrm{HCY)} \mathrm{can} \mathrm{compete} \mathrm{with} \mathrm{glycine}$ for the NMDAR co-agonist binding sites (Lipton et al., 1997). Recently, effects of HCY at relatively high concentrations (up to $1 \mathrm{mM}$ ) on NMDA and glutamate activated currents transferred through the channels of recombinant NMDARs composed of the GluN1 and GluN2A, GluN1 and GluN2B or GluN1 and GluN2D subunits were studied (Bolton et al., 2013). It has been demonstrated, that HCY can differently modulate peak amplitude of currents activated by NMDA and glutamate and reduce NMDAR desensitization caused by NMDA and glutamate depending on GluN2 subunit compositions (Bolton et al., 2013). Thus, several groups suggested that neuronal NMDARs may represent an important target for the action of elevated HCY (Kim and Pae, 1996; Lipton et al., 1997; Ganapathy et al., 2011; Poddar and Paul, 2013). Nevertheless, the specific features, associated with the action of HCY on NMDARs composed of the "synaptic type" GluN2A subunit and the "extrasynaptic type" GluN2B subunit are still missing.

An accumulation of HCY in the cerebrospinal fluid mentioned above is associated with severe pathologies and dysfunctions of the human central nervous system. As a wide population of patients suffers from hyperhomocysteinemia, a new knowledge of the precise receptor mechanisms of neuronal HCY effects may potentially improve a therapeutic strategy of these diseases. In addition, a discrepancy in mechanisms, by which HCY activates NMDARs composed of different GluN2 subunits may provide important information for NMDAR physiology. Therefore, in order to clarify subunit-specific properties of HCY action on NMDARs we studied its effects on native NMDARs in rat cortical neurons and recombinant GluN1/2A and GluN1/2B receptors expressed in HEK293T cells.
Here, we report that GluN2A subunit-containing NMDARs represent the preferential targets for HCY and mainly contribute to neuronal pathogenesis during hyperhomocysteinemia through activation of synaptic GluN1/2A receptors.

\section{MATERIALS AND METHODS}

\section{Primary Culture of Cortical Neurons}

The procedure of culture preparation from rat embryos was previously described (Antonov et al., 1998; Mironova et al., 2007). All procedures using animals were in accordance with recommendations of the Federation for Laboratory Animal Science Associations and approved by the local Institutional Animal Care and Use Committees. Wistar rats (provided by the Sechenov Institute's Animal Facility) 16 days pregnant (overall 12 animals in this study) were sacrificed by $\mathrm{CO}_{2}$ inhalation. Fetuses were removed and their cerebral cortices were isolated, enzymatically dissociated, and used to prepare primary neuronal cultures. Cells were used for experiments after 10-15 days in culture (Mironova et al., 2007; Han and Stevens, 2009). Cells were grown in Neurobasal ${ }^{\mathrm{TM}}$ culture medium supplemented with B-27 (Gibco-Invitrogen, UK) on glass coverslips coated with poly-D-lysine.

\section{HEK293T Cells with Recombinant NMDAR}

Human embryonic kidney (HEK) 293T cells were maintained as previously described (Qian et al., 2005). HEK293T cells were plated onto $7 \mathrm{~mm}$ glass coverslips pretreated with poly-L-lysine $(0.2 \mathrm{mg} / \mathrm{ml})$ in $35 \mathrm{~mm}$ culture dishes at $1 \times 10^{5}$ cells per dish. 18-24 h after plating cells were transiently transfected with a pcDNA1 plasmid encoding either rat NMDA receptor subunit GluN2A or GluN2B, and pcDNA3.1 plasmids encoding GluN1 and EGFP using FuGene HD reagent (Promega, Madison, WI, USA). Briefly, transfection was performed by adding to each dish $50 \mu \mathrm{l}$ serum-free medium containing $1 \mu \mathrm{g}$ total DNA and $2 \mu \mathrm{FuGene}$. The ratio of cDNA used was 1 EGFP: 1 GluN1: 3 GluN2 (A or B). After incubation of cells for $6-8 \mathrm{~h}$ the transfection solution was replaced with fresh culture medium containing $200 \mu \mathrm{M}$ DL-2-amino-5-amino-5-phosphono-valeric acid (DL-AP-5) and $2 \mathrm{mM} \mathrm{Mg}^{2+}$ to prevent NMDA receptor mediated-excitotoxicity. Experiments were performed 24-72 h after transfection. Mammalian expression vectors were supplied by Dr. J. W. Johnson (University of Pittsburgh, Pittsburgh, PA, USA).

\section{Patch Clamp Recordings}

Whole-cell patch clamp recordings of membrane currents were performed on cultured rat cortical neurons (10-15 DIV) and HEK293T cells expressing recombinant GluN1/2A or GluN1/2B receptors. We used a MultiClamp 700B patch-clamp amplifier with Digidata 1440A acquisition system controlled by pClamp v10.2 software (Molecular Devices, Sunnyvale, CA, USA). The signal was 8-order low-pass Butterworth filtered at $200 \mathrm{~Hz}$ to remove high frequency noise. Acquisition rate was 
$20000 \mathrm{~s}^{-1}$. Micropipette positioning was made with an MP-85 micromanipulator (Sutter Instrument, Novato, CA, USA) under visual control using a Nikon Diaphot TMD microscope (Nikon, Japan). For fast medium exchange we used a BPS-4 fast perfusion system (ALA Scientific Instruments, Farmingdale, NY, USA). The tip of the multichannel manifold was placed at a distance of $0.2 \mathrm{~mm}$ from the patched cell, allowing solution exchange in $80 \mathrm{~ms}$. Unless otherwise specified the following extracellular medium was used for recording (external bathing solution, in mM): $140 \mathrm{NaCl} ; 2.8 \mathrm{KCl} ; 1.0 \mathrm{CaCl}_{2} ; 10 \mathrm{HEPES}$, at $\mathrm{pH} 7.2-$ 7.4. Patch-pipette solution had the following composition (in $\mathrm{mM}): 120 \mathrm{CsF}, 10 \mathrm{CsCl}, 10 \mathrm{EGTA}$, and $10 \mathrm{HEPES}$. The $\mathrm{pH}$ was adjusted to 7.4 with $\mathrm{CsOH}$. Measured osmolarities of the external bathing solution and the patch-pipette solution were 310 and $300 \mathrm{mOsm}$, respectively. Patch pipettes (2-4 M $\Omega$ ) were pulled from 1.5-mm (outer diameter) borosilicate standard wall capillaries with inner filament (Sutter Instrument, Novato, CA, USA). Experiments were performed at room temperature (23$25^{\circ} \mathrm{C}$ ). In whole-cell configuration the series resistances did not exceed $10 \mathrm{M} \Omega$. After correction for the liquid junction potential between the $\mathrm{Na}^{+}$-containing external bathing solution and the $\mathrm{Cs}^{+}$-containing pipette solution of $-15 \mathrm{mV}$ the default membrane voltage $\left(\mathrm{V}_{\mathrm{m}}\right)$ was set to $-55 \mathrm{mV}$ for neurons and $-35 \mathrm{mV}$ for HEK293T cells. Functional activity of NMDARs requires binding of both glutamate and a co-agonist, glycine. Unless otherwise stated, to activate NMDARs we applied $50 \mu \mathrm{M}$ L-HCY (HCY) or $30 \mu \mathrm{M}$ NMDA with $30 \mu \mathrm{M}$ L-glycine (Gly).

\section{Loading of Fluo-3 AM and $\mathrm{Ca}^{2+}$ Imaging}

Cells were loaded with Fluo-3 AM ( $4 \mu \mathrm{M}$, Life Technologies, Foster City, CA, USA) using conventional protocols as recommended by the manufacturer. In brief, neuronal cultures were incubated with Fluo-3 AM for $45 \mathrm{~min}$ in the dark at room temperature. Then, Fluo-3 AM was washed out, and cells were incubated in the external solution for another $30 \mathrm{~min}$ in the dark. Coverslips with Fluo-3-loaded cultures were placed in the perfusion chamber, which was mounted on the stage of a Leica TCS SP5 MP inverted microscope (Leica Microsystems, Germany). Fluorescence was activated with $488 \mathrm{~nm}$ laser light and emission was measured within the wavelength range from 500 to $560 \mathrm{~nm}$. Images were captured every minute during 60 min experiments. In $\mathrm{Ca}^{2+}$ imaging experiments to activated NMDARs $100 \mu \mathrm{M}$ DL-HCY and $30 \mu \mathrm{M}$ Gly were used.

\section{Drugs}

Compounds were from Sigma-Aldrich, St. Louis, MO, USA.

\section{Data Analysis}

Quantitative data are expressed as mean \pm SEM. ANOVA and Bonferroni multiple comparison methods as well as Student's two-tailed $t$-test were used for statistical analysis. Number of experiments is indicated by $n$ throughout. The data were considered as significantly different based on a confidence level of 0.05. Current measurements were plotted using ClampFit 10.2 (Molecular Devices). The $\mathrm{EC}_{50}$ (half-maximal effective concentration for HCY as an agonist) and Hill coefficient $(h)$ were estimated by fitting of concentration-response curves with the Hill equation, $\mathrm{I}_{[\mathrm{HCY}]} / \mathrm{I}_{\max }=1 /\left(1+\mathrm{EC}_{50}{ }^{h} /[\mathrm{HCY}]^{h}\right)$, where the $\mathrm{I}_{\max }$ is the current of maximal amplitude elicited by HCY and $\mathrm{I}_{[\mathrm{HCY}]}$ are the current amplitudes measured at each [HCY].

\section{RESULTS}

\section{Amplitude and Dynamic Difference of Neuronal Responses to HCY and NMDA}

As the starting point for evaluation of agonist properties of $\mathrm{HCY}$, we compared intracellular $\mathrm{Ca}^{2+}$ responses $\left(\left[\mathrm{Ca}^{2+}\right]_{\mathrm{i}}\right)$ elicited by NMDA and HCY in non-patched cortical neurons. Figure 1A shows that application of $100 \mu \mathrm{M}$ DL-HCY induced fast $\mathrm{Ca}^{2+}$ responses, which quickly decayed to the baseline and often were followed by small repetitive waves. In contrast, application of $30 \mu \mathrm{M}$ NMDA activated typical sustained $\left[\mathrm{Ca}^{2+}\right]_{\mathrm{i}}$ responses of comparable amplitude, that lasted as long as NMDA was present (Figure 1A). As the $\left[\mathrm{Ca}^{2+}\right]_{\mathrm{i}}$ increase could be determined by $\mathrm{Ca}^{2+}$ entry through the NMDARs, voltage gated calcium channels, and/or $\mathrm{Ca}^{2+}$ release from intracellular stores, we next explored the action of HCY using patch clamp technique. Consistent with the different shape of $\mathrm{Ca}^{2+}$ responses, membrane currents activated by $50 \mu \mathrm{M}$ HCY differed from currents activated by $30 \mu \mathrm{M}$ NMDA, both in amplitude and time course. Although in some cells, HCY and NMDA activated currents of comparable peak amplitude (Figure 1B, top), the average peak amplitude of currents activated by HCY was significantly less than of currents activated by NMDA (Figure 1C). However, the most notable difference was the relative level of the steady-state currents. Figure 1D demonstrates that the ratio of steady-state amplitudes to peak amplitudes was significantly smaller for HCY activated currents than for NMDA activated currents. In almost all cases the steady-state current amplitude was much lower when activated by HCY than when activated by NMDA (Figures 1B,C). Thus, both $\mathrm{Ca}^{2+}$-imaging and patch clamp recording data uncovered essential differences between the actions of HCY and NMDA on native NMDARs in cortical neurons.

\section{Pharmacological Features of Neuronal Responses to HCY}

We further compared pharmacological characteristics of currents activated by HCY and NMDA. An antagonist of mGluR5, 3((2-methyl-4-thiazolyl)ethynyl)pyridine (MTEP), did not affect HCY-induced currents under experimental conditions used here, suggesting that activation of mGluR5 does not contribute to the currents activated by HCY (data not shown). Competitive antagonist of NMDARs (2R)-amino-5-phosphonopentanoate (AP-5), caused almost complete block of HCY-induced currents (Figures 2A,D) suggesting that the currents were indeed transferred through the NMDAR channels. Notably, the currents activated by HCY at steady state were resistant to the action of ifenprodil (Figures 2B,D). In contrast, this GluN2B subunit selective inhibitor (Williams, 1993) efficiently blocked currents activated by NMDA (Figures 2C,D). 


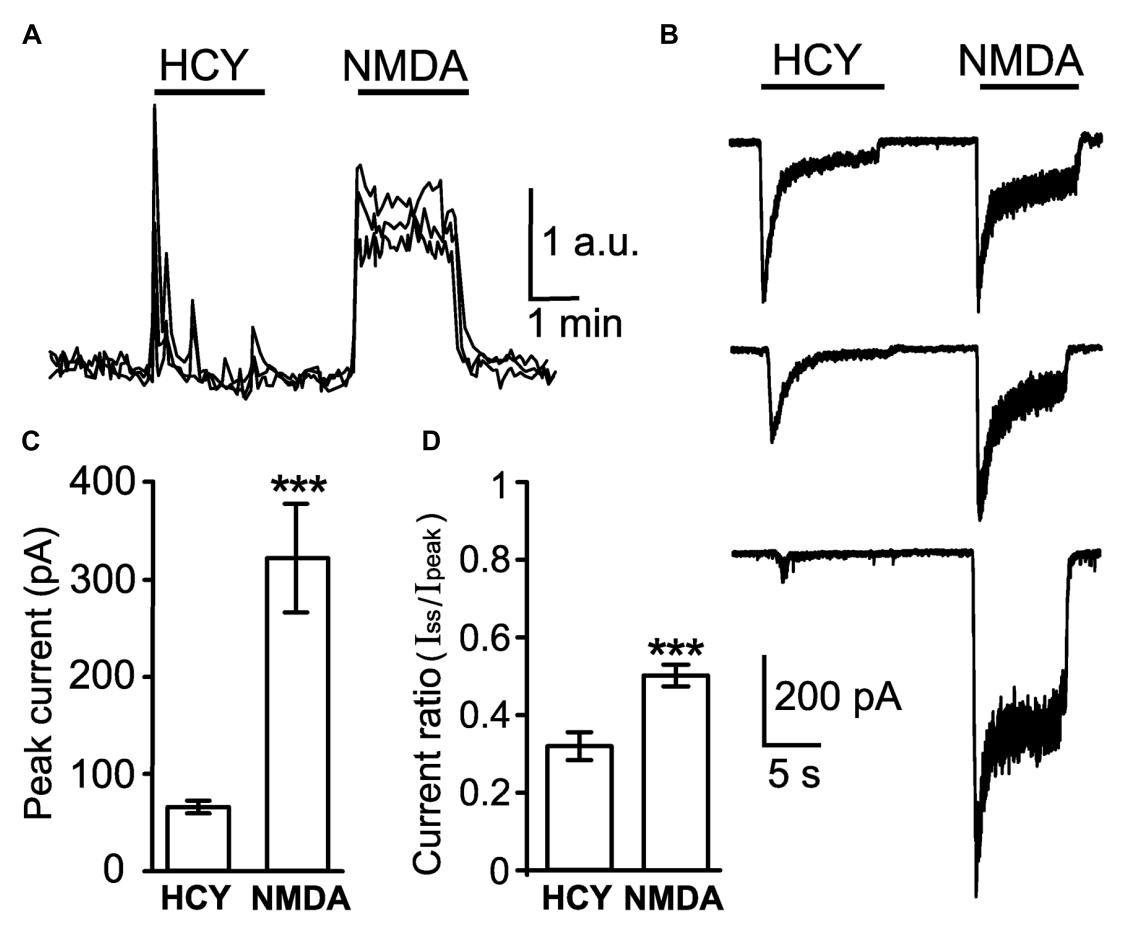

FIGURE 1 | Comparison of neuronal responses to NMDAR agonists. (A) $\mathrm{Ca}^{2+}$ responses induced by $100 \mu \mathrm{M}$ DL-HCY and $30 \mu \mathrm{M}$ NMDA in the presence of $30 \mu \mathrm{M}$ Gly applied for $2 \mathrm{~min}$ to neurons loaded with Fluo-3 AM. Traces represent an overlay of neuronal responses (four neurons). Application protocol is shown above the traces. (B) Whole-cell currents activated in neurons by application of $50 \mu \mathrm{M} \mathrm{HCY}$ and $30 \mu \mathrm{M}$ NMDA in the presence of $30 \mu \mathrm{M}$ Gly recorded at

$V_{m}=-55 \mathrm{mV}$. (C) Quantitative comparison of peak amplitudes of currents activated by $50 \mu \mathrm{M} \mathrm{HCY}$ and $30 \mu \mathrm{M}$ NMDA in the presence of $30 \mu \mathrm{M}$ Gly recorded from the same neurons $(n=57)$ at $\mathrm{V}_{\mathrm{m}}=-55 \mathrm{mV}$ during paired agonist applications. Data differ significantly $\left({ }^{* * *} p<0.0001\right.$, two-tailed Student's $t$-test). (D) Quantitative comparison of steady-state amplitude $\left(I_{s s}\right)$ to peak amplitude $\left(l_{p e a k}\right)$ ratios of currents activated by HCY and NMDA during paired applications. Data differ significantly $\left({ }^{* * *} p<0.0001\right.$, two-tailed Student's $t$-test).

Taken together, these experiments demonstrated considerable pharmacological differences between NMDA and HCY as agonists of NMDARs.

\section{NMDAR Desensitization Induced by NMDA and HCY in Neurons}

Since different agonists of NMDARs can induce NMDAR desensitization of different onset and offset rates (Lester and Jahr, 1992), we further studied desensitization of NMDARs caused by NMDA and HCY in cortical neurons.

Currents activated by NMDA declined to a steady-state level because of receptor desensitization (Figure 3A). The time constant of desensitization onset $\left(\tau_{\text {on }}\right)$ was measured by fitting the decay of NMDAR mediated currents to steady state with a single exponential function (Figure 3A). In the presence of $\mathrm{Ca}^{2+}$ in the external bathing solution the $\tau_{\text {on }}$ value for NMDA induced currents was $1.6 \pm 0.1 \mathrm{~s}(n=36)$.

In the case of HCY, currents also declined to the steady-state level (Figure 3B). The $\tau_{\text {on }}$ for HCY was $1.6 \pm 0.2 \mathrm{~s}(n=47)$ and did not differ significantly from NMDAR desensitization caused by NMDA ( $p>0.8$, Student's two-tailed $t$-test, Figure 3C).

In $\mathrm{Ca}^{2+}$-free external bathing solution, however, the currents activated by NMDA did not decrease in time, revealing the lack of desensitization (Figures 3A,D). In sharp contrast, the onset of desensitization caused by HCY remained unchanged $\left(\tau_{\text {on }}=1.2 \pm 0.2 \mathrm{~s}, n=34\right.$, Figures $\left.3 \mathrm{~B}-\mathrm{D}\right)$. These data demonstrated that NMDA-induced responses were characterized by $\mathrm{Ca}^{2+}$-dependent desensitization (Legendre et al., 1993; Zhang et al., 1998; Sibarov et al., 2015), whereas desensitization of HCY-induced responses was almost $\mathrm{Ca}^{2+}$-independent.

In order to estimate the time constant of recovery from desensitization induced by NMDA and HCY for native NMDARs we used a double application protocol consisting of 4-12 repeats. In this protocol, the second application of the agonists in the next repeat was applied with an incrementing delay of 1-2 s from the first. The increment duration was chosen to achieve a best resolution of the desensitization offset (Figures 4A,B). The recovery from desensitization was measured as an increase of current amplitudes in the sequence of second agonist applications which was well-fitted by a single exponential function with a time constant ( $\tau_{\text {off }}$ ) of the desensitization offset (Figure $4 \mathrm{C}$ ). Whereas, the $\tau_{\text {on }}$ values of the native NMDAR desensitization onset caused by NMDA and HCY were similar (Figure $3 \mathrm{C}$ ), the $\tau_{\text {off value for }}$ NMDA elicited currents was significantly larger, than those for HCY $(p<0.0001$, Student's two-tailed $t$-test) and were $6.3 \pm 1.1$ $(n=6)$ and $2.5 \pm 0.5 \mathrm{~s}(n=5)$, respectively (Figure 4C).

The removal of $\mathrm{Ca}^{2+}$ from the external bathing solution nearly abolished the amplitude decrease of NMDA-activated currents (Figure 4D) demonstrating the $\mathrm{Ca}^{2+}$ dependence of NMDAR desensitization. In contrast the decrease of currents 
A

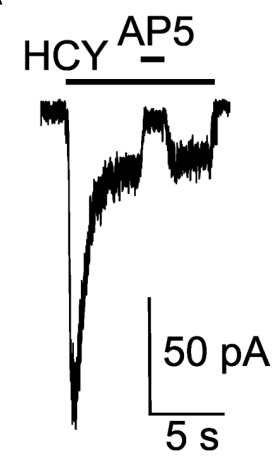

B

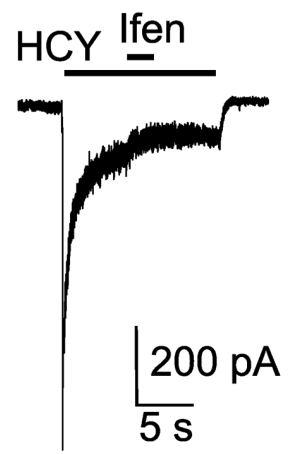

C

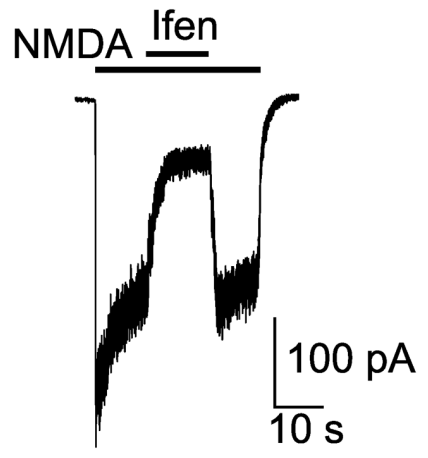

D

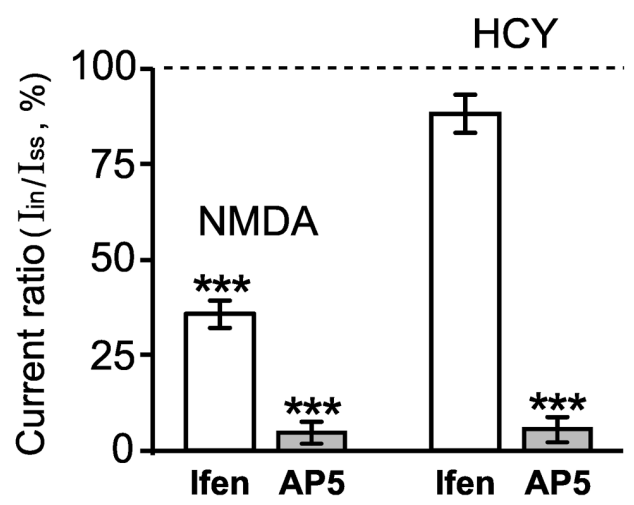

FIGURE 2 | Pharmacological properties of neuronal currents activated by HCY and NMDA. (A) Representative current trace recorded in a neuron at $V_{\mathrm{m}}=-55 \mathrm{mV}$ activated by $50 \mu \mathrm{M} \mathrm{HCY}+30 \mu \mathrm{M}$ Gly. After current reached steady state, $100 \mu \mathrm{M}$ AP- 5 was applied. The application protocol is shown above the trace. (B) Representative current trace recorded in a neuron at $V_{m}=-55 \mathrm{mV}$ activated by $50 \mu \mathrm{M} \mathrm{HCY}+30 \mu \mathrm{M}$ Gly. After current reached steady state, $5 \mu \mathrm{M}$ ifenprodil (ifen) was applied. The application protocol is shown above the trace. (C) Representative current trace recorded in a neuron at $V_{\mathrm{m}}=-55 \mathrm{mV}$ activated by $30 \mu \mathrm{M}$ NMDA $+30 \mu \mathrm{M}$ Gly. After current reached steady state, $5 \mu \mathrm{M}$ ifenprodil (ifen) was applied. The application protocol is shown above the trace. (D) Quantitative comparison of inhibition of NMDA-activated currents caused by $5 \mu \mathrm{M}$ ifenprodil (ifen, $n=18$ ) and $100 \mu \mathrm{M} \mathrm{AP-5}(n=24)$ and inhibition of HCY-activated currents caused by $5 \mu \mathrm{M}$ ifenprodil (ifen, $n=26)$ and $100 \mu \mathrm{M}$ AP-5 $(n=9)$. Ordinate axis - ratio of the current amplitude obtained during inhibition (lin) to the steady-state current amplitude $\left(I_{s S}\right)$ obtained without antagonists. Data differ significantly from steady-state current control amplitudes $(* * * p<0.0006$, ANOVA, post hoc Bonferroni test).

activated by HCY remained unchanged (Figure 4E) in the $\mathrm{Ca}^{2+}$ free media suggesting that native NMDAR desensitization evoked by $\mathrm{HCY}$ is not $\mathrm{Ca}^{2+}$ - dependent. Moreover, the $\tau_{\text {off }}$ value of HCY induced desensitization ( $\tau_{\text {off }}=2.7 \pm 0.7 \mathrm{~s}, n=4$, Figure $4 \mathrm{~F}$ ) obtained in the $\mathrm{Ca}^{2+}$-free media was similar to the $\tau_{\text {off }}$ value found in the presence of $\mathrm{Ca}^{2+}$ in the external bathing solution ( $\tau_{\text {off }}=2.5 \pm 0.5 \mathrm{~s}, n=5$, Figure $4 \mathrm{C}$ ) and did not differ significantly ( $p>0.85$, Student's two-tailed $t$-test).

Overall, the above experiments reveal substantial kinetic, amplitude, and pharmacological differences between currents activated by NMDA and HCY in cortical neurons as well as specific properties of desensitization with respect to $\mathrm{Ca}^{2+}$ dependence of this phenomenon.

\section{HCY Induces Fast Desensitization of Recombinant GluN1/2B NMDARs}

Because cortical neurons in primary culture typically express NMDARs of GluN1/2A and GluN1/2B subunit compositions (Zhong et al., 1994; Mizuta et al., 1998) we hypothesized that
HCY when activates these receptor subtypes may causes different kinetics of activation and desensitization.

To get more clues in the mechanism of HCY activation of NMDARs, we performed experiments on recombinant GluN1/2A and GluN1/2B receptors expressed in HEK293T cells. $50 \mu \mathrm{M}$ HCY applied to cells expressing diheteromeric GluN1/2A receptors caused robust inward currents, which did not reveal decrease of amplitude during $10 \mathrm{~s}$ applications, suggesting a lack of GluN1/2A receptor desensitization (Figure 5A). Application of $100 \mu \mathrm{M}$ Glu (a saturating concentration for GluN1/2A receptor, see Traynelis et al., 2010), induced currents which were similar in amplitude to those activated by HCY (Figure 5B). In the case of Glu, these currents largely decreased to steady state because of the receptor desensitization (Figure 5A). For GluN1/2A receptors, the application of $30 \mu \mathrm{M}$ NMDA induced currents that were much smaller than those activated by HCY or Glu. Mean amplitude of NMDA activated currents differed from mean amplitudes of HCY and Glu activated currents significantly $(p<0.0001$, ANOVA, post hoc Bonferroni test, 

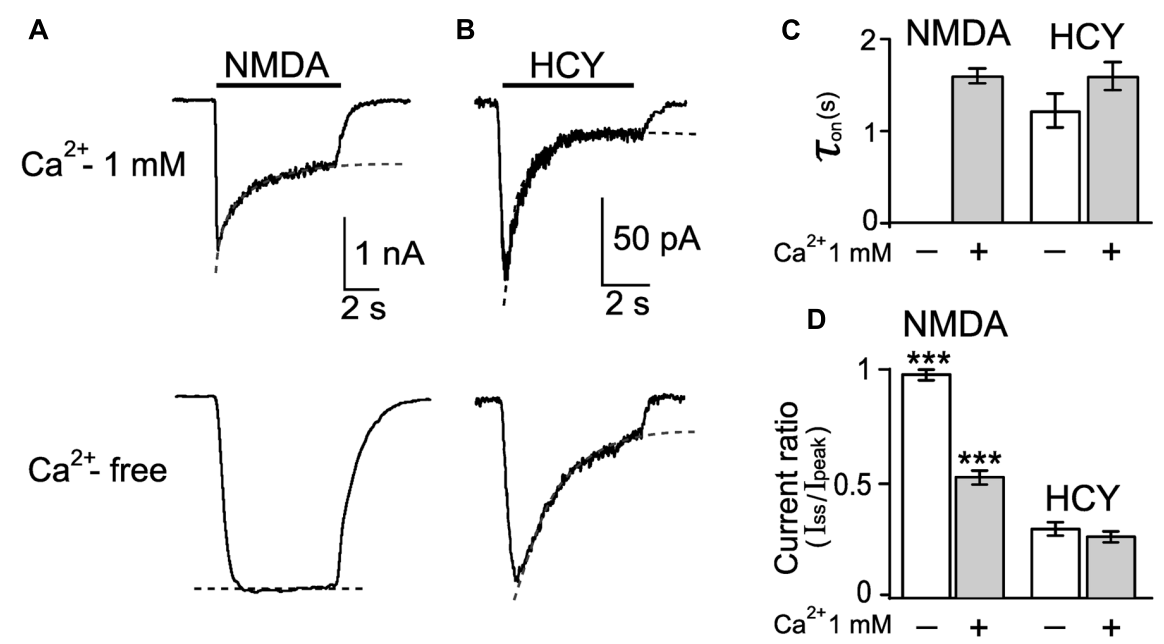

FIGURE 3 | Desensitization of native NMDARs caused by NMDA and HCY. (A) Currents activated by $30 \mu \mathrm{M}$ NMDA $+30 \mu \mathrm{M}$ Gly in neurons recorded at $V_{m}=-55 \mathrm{mV}$ in the presence and absence of $\mathrm{Ca}^{2+}$ in the external bathing solutions. Dotted lines represent fits of a single exponential function to current decays. (B) Currents activated by $50 \mu \mathrm{M} \mathrm{HCY}+30 \mu \mathrm{M}$ Gly in neurons recorded at $\mathrm{V}_{\mathrm{m}}=-55 \mathrm{mV}$ in the presence and absence of Ca ${ }^{2+}$ in the external bathing solutions. Dotted lines represent fits of single exponential function to current decays. (C) Quantitative comparison of NMDAR desensitization onsets evoked by NMDA and $\mathrm{HCY}$ in the presence and absence of $\mathrm{Ca}^{2+}$ in the external bathing solution. $\tau_{\text {on }}$ was measured as the time constant of current decay to the steady-state level. Data do not differ $(p>0.36$, ANOVA, $n=10$ ). (D) Quantitative comparison of NMDAR desensitization evoked by NMDA and HCY in the presence and absence of Ca $2+$ in the external bathing solution. Ordinate axis - ratio of amplitudes obtained at steady-state $\left(I_{\text {ss }}\right)$ and peak ( $\left.\left.\right|_{\text {peak }}\right)$ current as a measure of desensitization. Values differ significantly from data, obtained with $\mathrm{HCY}(* * * p<0.001$, ANOVA, post hoc Bonferroni test, $n$ varied from 16 to 56 for different data sets).

$n=37$, Figures 5 A, B), because of the NMDA concentration used in these experiments is much smaller than a saturating one. The data obtained with Glu and NMDA are consistent with known efficacy and $\mathrm{EC}_{50}$ of Glu and NMDA as agonists of GluN1/2A NMDARs (for review, see Traynelis et al., 2010).

In contrast to GluN1/2A receptors, applications of $50 \mu \mathrm{M}$ HCY to cells expressing diheteromeric GluN1/2B receptors caused currents that initially peaked and then declined to steady state of small amplitude (Figure 5C). $100 \mu \mathrm{M}$ Glu and $30 \mu \mathrm{M}$ NMDA induced large GluN1/2B mediated currents (Figure 5C) that did not differ significantly in their steady-state amplitudes (Figure 5D). The steady-state current amplitudes achieved during applications of HCY were very small in comparison to currents obtained in the presence of Glu and NMDA and differed from them significantly $(p<0.0001$, ANOVA, post hoc Bonferroni test, $n=57$ ). The data obtained with respect to Glu and NMDA are consistent with the known efficacy and $E_{50}$ of these agonists to binding sites on GluN1/2B NMDARs (for review, see Traynelis et al., 2010).

Thus, HCY is an effective agonist of NMDARs of both GluN1/2A and GluN1/2B subunit compositions. GluN1/2A receptors, however, do not exhibit desensitization during activation by HCY, whereas the activation of GluN1/2B receptors by HCY was accompanied by fast and close to complete desensitization.

\section{HCY as High Affinity Agonist of Recombinant GluN1/2A NMDARs}

In further experiments, we measured the potency $\left(\mathrm{EC}_{50}\right.$ values) for activation of HCY currents mediated by native and recombinant GluN1/2A and GluN1/2B NMDARs. First, a saturating concentration of HCY in the presence of $30 \mu \mathrm{M}$ Gly was applied to neurons or HEK293T cells expressing GluN1/2A and GluN1/2B NMDARs. Then the HCY concentration was decreased until currents could not be activated (Figure 6A). For each of NMDAR type the progressive lowering of HCY concentration caused a decrease of NMDAR current amplitude measured at steady state (Figure 6A). The dependence of the steady-state current amplitude on HCY concentration is shown in Figure 6B. Fits of the Hill equation to the data revealed the apparent dissociation constants $\left(\mathrm{EC}_{50}\right)$ for HCY with NMDARs and the Hill coefficients $(h)$ which were $14.4 \pm 1.3 \mu \mathrm{M}$ and $h=1.8 \pm 0.8(n=6)$ for native NMDARs, $9.7 \pm 1.8 \mu \mathrm{M}$ and $h=1.6 \pm 0.5(n=10)$ for GluN1/2A receptors, and $61.8 \pm 8.9 \mu \mathrm{M}$ and $h=2.1 \pm 0.3(n=10)$ for GluN1/2B receptors. Whereas, the $\mathrm{HCY} \mathrm{EC}_{50}$ values for GluN1/2A and native receptors do not differ significantly, they are significantly smaller than the $\mathrm{EC}_{50}$ value for GluN1/2B receptors $(p<0.0001$, ANOVA, post hoc Bonferroni test, Figure 6C). Therefore, HCY can be considered a high potency agonist of NMDARs composed by the GluN1/2A subunits. The similarity between the HCY $\mathrm{EC}_{50}$ values obtained on the native and GluN1/2A NMDARs, may suggest that the currents, activated by HCY in neurons, at the steady state are predominantly mediated by diheteromeric GluN1/2A NMDARs.

\section{DISCUSSION}

The main finding of this study is that the endogenous amino acid, HCY, implicated in various brain diseases preferentially 


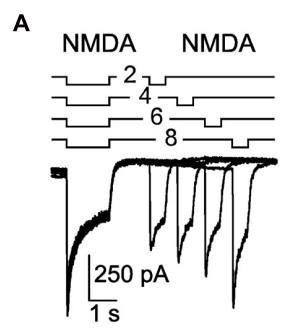

D

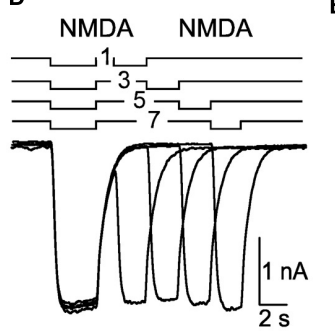

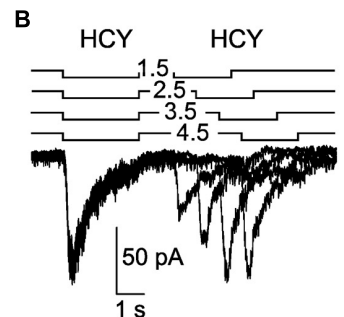

$1 \mathrm{~s}$

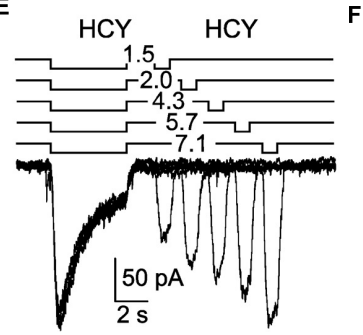

c

$\mathbf{F}$
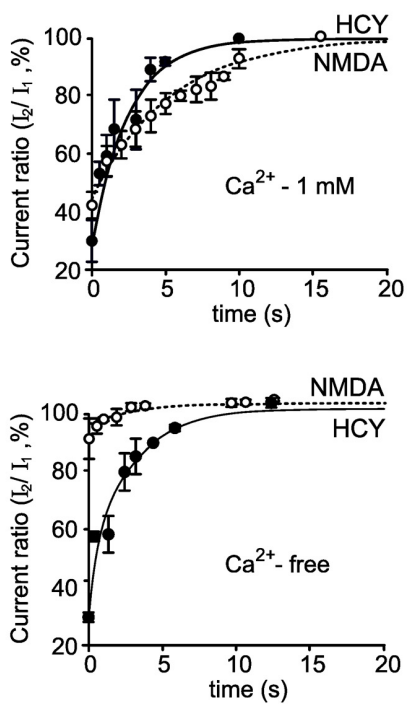

FIGURE 4 | Recovery from desensitization induced by NMDA and HCY. (A) An overlay of currents activated by $30 \mu \mathrm{M}$ NMDA $+30 \mu \mathrm{M}$ Gly using the paired application protocol (shown above the traces) recorded in the neuron at $\mathrm{V}_{\mathrm{m}}=-55 \mathrm{mV}$ in the presence of $\mathrm{Ca}^{2+}$ in the external bathing solution. (B) An overlay of currents activated by $50 \mu \mathrm{M} \mathrm{HCY}+30 \mu \mathrm{M}$ Gly using the paired application protocol (shown above the traces) recorded in the neuron at $\mathrm{V}_{\mathrm{m}}=-55 \mathrm{mV}$ in the presence of $\mathrm{Ca}^{2+}$ in the external bathing solution. (C) The dependence of the peak current amplitude achieved during the second agonist application on the duration of delay between applications. Ordinate axis - ratio of the peak amplitudes of the current elicited by the second application $\left(I_{2}\right)$ to the current elicited by the first application $\left(l_{1}\right)$. The peak amplitude of currents activated by the first application was taken for $100 \%$. Open circles - the data obtained by NMDA applications ( $n=6$ for each point). Filled circles - the data obtained by HCY applications ( $n=5$ for each point). Lines represent fits of a single exponential function to the data points. (D) An overlay of currents activated by $30 \mu \mathrm{M}$ NMDA + $30 \mu \mathrm{M}$ Gly using the paired application protocol (shown above the traces) recorded in the neuron at $V_{\mathrm{m}}=-55 \mathrm{mV}$ in $\mathrm{Ca}^{2+}$-free media. (E) An overlay of currents activated by $50 \mu \mathrm{M} \mathrm{HCY}+30 \mu \mathrm{M}$ Gly using the paired application protocol (shown above the traces) recorded in the neuron at $V_{m}=-55 \mathrm{mV}$ in $\mathrm{Ca}^{2+}$-free media. (F) The dependence of the peak current amplitude achieved during the second agonist application on the duration of delay between applications. Ordinate axis - ratio of the peak amplitudes of the current elicited by the second application $\left(I_{2}\right)$ to the current elicited by the first application $\left(I_{1}\right)$. The peak amplitude of currents activated by the first application was taken for $100 \%$. Open circles - the data obtained by NMDA applications ( $n=6$ for each point). Filled circles - the data obtained by HCY applications ( $n=4$ for each point). Lines represent fits of a single exponential function to the data points.

activates "synaptic type" GluN2A subunit-containing NMDA receptors with specific kinetics properties including limited receptor desensitization.

\section{HCY Signaling in Brain}

Homocysteine that accumulates in plasma during hyperhomocysteinemia can potentially lead to the death of cortical neurons (Lipton et al., 1997; Abushik et al., 2014), retinal ganglion cells (Ganapathy et al., 2011) and trigeminal neurons (Abushik et al., 2014). This type of excitotoxicity is likely mediated by activation of native NMDARs (Lipton et al., 1997; Ganapathy et al., 2011; Bolton et al., 2013; Abushik et al., 2014).

The goal of our study was to clarify the mechanism of HCY action on cortical neurons. In order to succeed in addressing this goal, we compared HCY action on recombinant NMDARs of known composition. GluN1/2A and GluN1/2B receptors in different regions of adult brain exhibit preferentially synaptic and extrasynaptic locations, respectively, which are subjected for activity-dependent modulation and may change during pathogenesis (Paoletti et al., 2013). Notably, cortical neurons vary substantially with respect to GluN2A versus GluN2B expression ratio (Tovar and Westbrook, 1999; Traynelis et al., 2010). Our data in general are consistent with the view that HCY is an agonist of NMDAR glutamate binding sites (Lipton et al., 1997; Ganapathy et al., 2011; Bolton et al., 2013). This would suggest that neuronal responses of NMDARs to HCY, Glu or NMDA used at equally potent concentrations should have similar amplitudes and time courses. However, in this study we found that HCY-induced intracellular $\mathrm{Ca}^{2+}$ responses as well as NMDAR-mediated currents differ greatly with respect to their amplitudes and time courses from responses to NMDA obtained on the same neurons. In contrast to NMDA, which activated sustained $\mathrm{Ca}^{2+}$ intracellular responses, $\mathrm{HCY}$ induced fast oscillatory intracellular $\mathrm{Ca}^{2+}$ transients which peaked and than briefly declined to the control $\left[\mathrm{Ca}^{2+}\right]_{\mathrm{i}}$. Currents activated by HCY also varied greatly by amplitudes between neurons, being generally much smaller (on average about 1/6), than the corresponding NMDA induced currents. Moreover, pharmacological analysis indicated that the steady-state currents, activated by HCY, were resistant to ifenprodil, a GluN2B selective inhibitor of NMDARs (Williams, 1993). Most striking, unlike $\mathrm{Ca}^{2+}$-dependent NMDA-induced desensitization, the NMDAR desensitization evoked by HCY did not depend on extracellular $\mathrm{Ca}^{2+}$. Thus, $\mathrm{Ca}^{2+}$-independent HCY desensitization could be defined as a ligand-dependent NMDAR desensitization (Lester and Jahr, 1992).

Taken together, these observations suggest that neuronal NMDAR currents, transferred through channels of GluN1/2A 
A
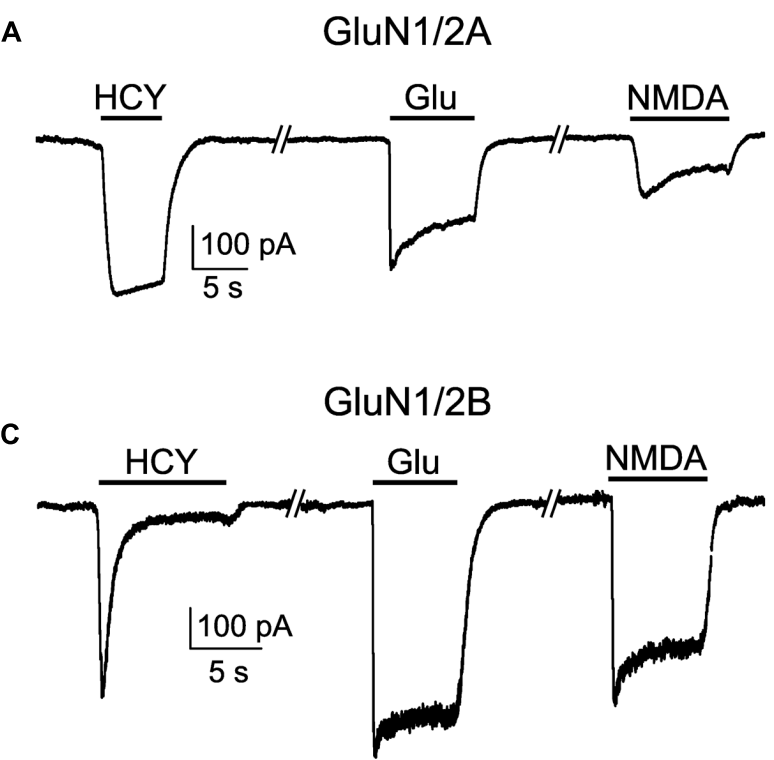

B

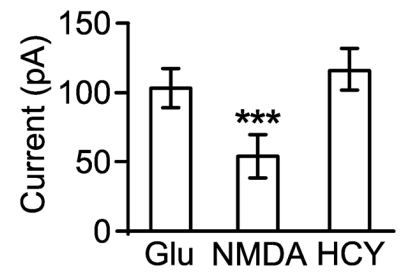

D

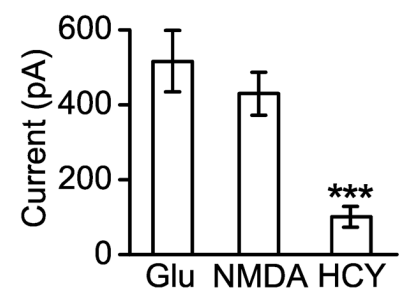

FIGURE 5 | Comparison of currents activated by HCY in HEK293T cells expressing recombinant GluN1/2A and GluN1/2B receptors. (A) Currents activated by $50 \mu \mathrm{M} \mathrm{HCY}, 100 \mu \mathrm{M}$ Glu, and $30 \mu \mathrm{M}$ NMDA in the presence of $30 \mu \mathrm{M}$ Gly recorded in HEK293T cells at $\mathrm{V}_{\mathrm{m}}=-35 \mathrm{mV}$ expressing NMDARs of GluN1/2A subunit compositions. (B) Histogram of the steady-state amplitudes of currents activated by these agonists in the same cells. The data are significantly different $\left({ }^{* * *} p<0.0001\right.$, ANOVA, post hoc Bonferroni test, $\left.n=37\right)$. (C) Currents activated by $50 \mu \mathrm{M} \mathrm{HCY,} 100 \mu \mathrm{M}$ Glu, and $30 \mu \mathrm{M}$ NMDA in the presence of $30 \mu \mathrm{M}$ Gly recorded in HEK293T cells at $V_{m}=-35 \mathrm{mV}$ expressing NMDARs of GluN1/2B subunit compositions. (D) Histogram of the steady-state amplitudes of currents activated by these agonists in the same cells. The data are significantly different $(* * *<0.0001$, ANOVA, post hoc Bonferroni test, $n=57)$.

and GluN1/2B receptors, have very different kinetics and pharmacological sensitivity when activated by HCY and NMDA.

\section{Role of Subunit Composition}

Our experiments on recombinant GluN1/2A and GluN1/2B NMDARs expressed in HEK293T cell disclosed the peculiarities of complex desensitization kinetics when native NMDARs were activated by HCY and NMDA. We found that HCY is a high potency agonist $\left(\mathrm{EC}_{50}\right.$ is about $\left.9 \mu \mathrm{M}\right)$ of GluN1/2A receptors. Remarkably, during HCY activation these receptors do not undergo desensitization. In contrast to GluN1/2A receptors, $\mathrm{HCY}$ is a low potency agonist of GluN1/2B receptors $\left(\mathrm{EC}_{50}\right.$ is about $70 \mu \mathrm{M})$. Furthermore, HCY promotes fast desensitization of GluN2B-containing receptors providing a low-level steadystate current. Recently, effects of HCY on currents activated by NMDA and Glu mediated by different recombinant NMDARs (containing GluN2A or GluN2B or GluN2C) were studied (Bolton et al., 2013). In agreement with our study the HCY effects appeared to be dependent on GluN2 subunits, suggesting deviations of the HCY effects on different GluN2. Indirectly this observation supports conclusions drown here.

Our data may allow plausible explanation of peculiarities in HCY action that determine amplitude and shape of native NMDAR currents in cortical neurons (Figure 7). Both subtypes of NMDARs contribute to currents activated by NMDA (Figure 7A) and, most likely, to the peak current activated by HCY. In case of HCY the peak current declines quickly because of the GluN1/2B receptor desensitization caused by HCY. Therefore, GluN1/2B receptors can contribute little to depolarization and $\mathrm{Ca}^{2+}$ transients induced by HCY in neurons during long-lasting periods of action (Figure 7B). As a result the steady-state currents activated in neurons by HCY are generally transferred through the channels of GluN1/2A receptors, which do not undergo desensitization. Our observation that HCY activated currents at steady state are resistant to ifenprodil is consistent to this explanation. In addition, because the GluN1/2B versus GluN1/2A expression ratio varies substantially between neurons the amplitudes of peak and steady-state components of currents activated by HCY could demonstrate considerable variability.

\section{Pathophysiological Implications}

The data predict that HCY may have different neuronal targets depending on NMDAR subunit compositions. One major distinction between the two receptor subtypes is that the GluN2A-containing NMDARs are thought to occur in post-synaptic regions and have exclusively synaptic location (Tovar and Westbrook, 1999; Momiyama, 2000; Steigerwald et al., 2000; Dalby and Mody, 2003; de Armentia and Sah, 2003, see also Figure 7). In opposite, NMDARs, which are supposed to contain the GluN2B subunit, are distributed over large extrasynaptic somatic and dendritic areas and mediate the synaptic cross talk sensing the neurotransmitter spillover during excessive synaptic activity (Scimemi et al., 2004). Interestingly, GluN2A- and GluN2B-containing NMDARs have been linked to different intracellular cascades contributing in LTP and LTD and also leading to preferential triggering neuroprotection and neurodegeneration, respectively (Hardingham and Bading, 2010; 


\section{A}

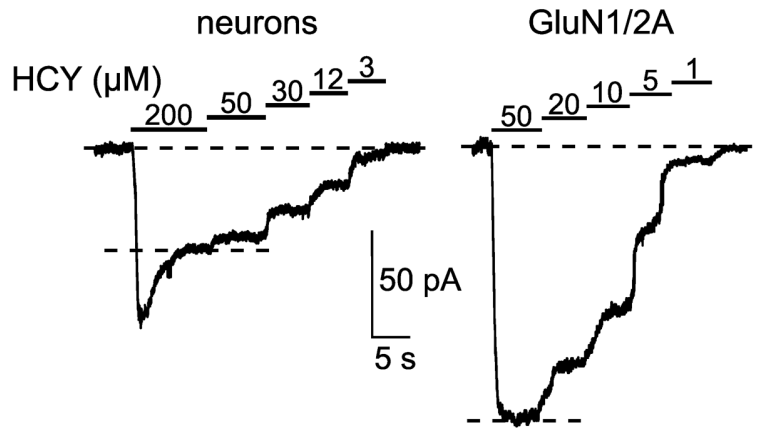

B
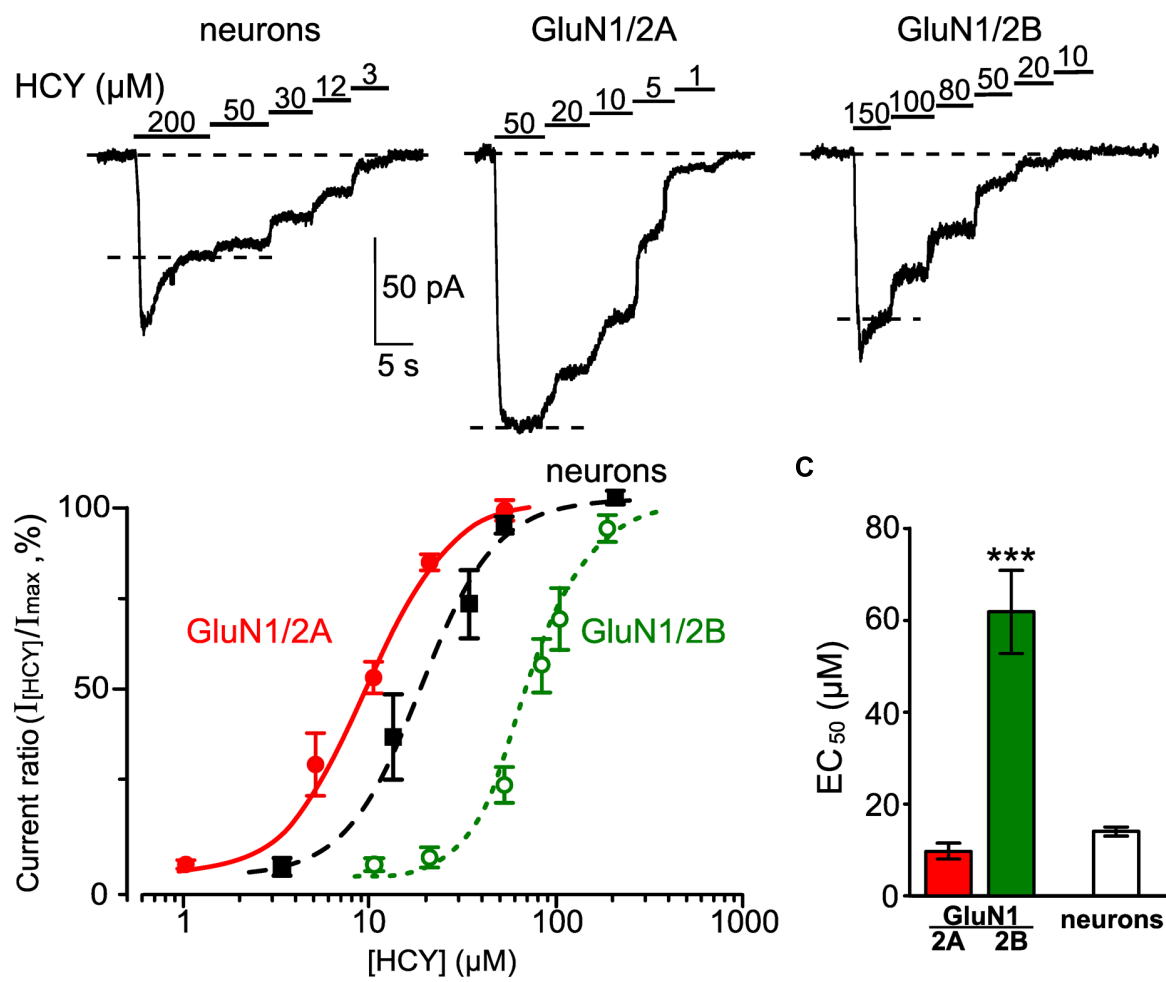

C

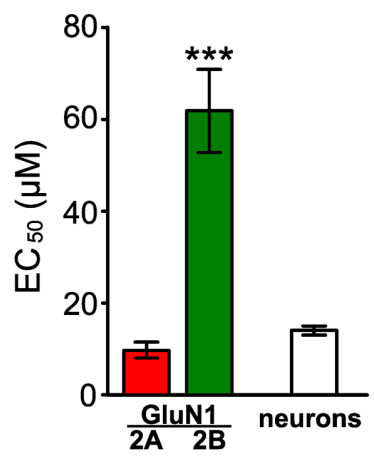

FIGURE 6 | Measurements of $\mathrm{EC}_{50}$ for $\mathrm{HCY}$ as an agonist of native NMDARs and recombinant NMDARs of GluN1/2A and GluN1/2B subunit compositions. (A) Currents elicited by the indicated HCY concentrations in the presence of $30 \mu \mathrm{M}$ Gly recorded in cortical neurons at $V_{\mathrm{m}}=-55 \mathrm{mV}$ and in HEK293T cells expressing recombinant GluN1/2A and GluN1/2B NMDARs at $V_{m}=-35 \mathrm{mV}$. Application protocols are indicated above the records. (B) Concentration-activation curves for HCY obtained for currents mediated by native NMDARs (filled squares) and recombinant NMDARs of GluN1/2A (filled circles) and GluN1/2B (open circles) subunit compositions. Ordinate axis - ratio of amplitudes obtained at steady state in the presence of different $\mathrm{HCY}$ concentrations $\left(\mathrm{l}_{[\mathrm{HCY}]}\right)$ to the maximal amplitude $\left(I_{\max }\right)$. Solid lines indicate fits of the data with the Hill equation. (C) Quantitative comparison of $\mathrm{EC}_{50} \mathrm{~S}$ for HCY activation of native and recombinant GluN2A- and GluN2B-containing NMDARs. Data are significantly different $(* * * p<0.0001$, ANOVA, post hoc Bonferroni test, $n=6-10)$.

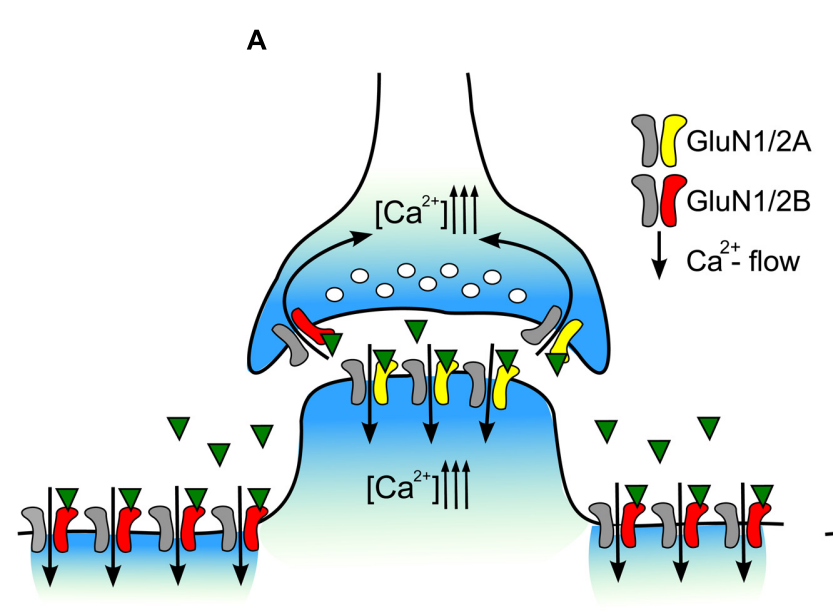

Glutamate excitotoxicity
B

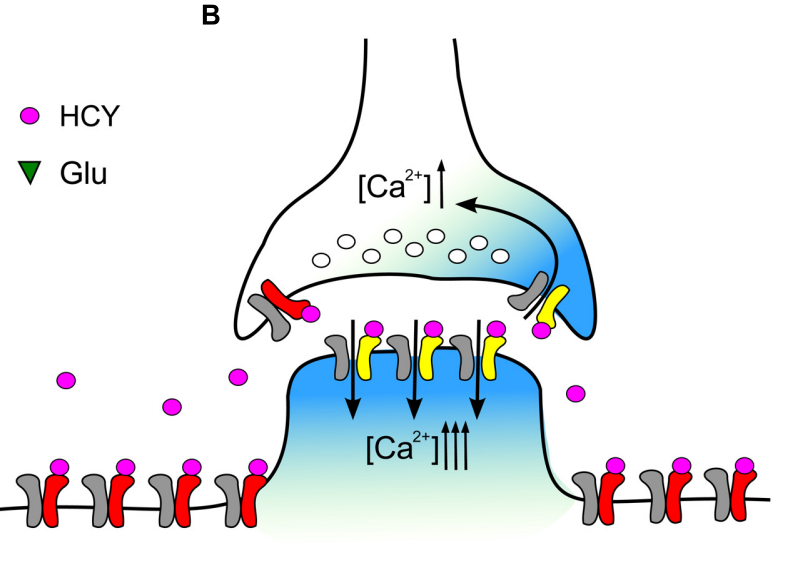

Hyperhomocysteinemia

FIGURE 7 | Schematics of the data interpretation. (A) During excitotoxic episodes Glu activates both extrasynaptic GluN2B-containng NMDARs and synaptic GluN2A-containing NMDARs. Entry of external $\mathrm{Ca}^{2+}$ into neurons through open NMDAR channels causes intracellular $\mathrm{Ca}^{2+}$ overload. (B) During hyperhomocysteinemia HCY desensitizes extrasynaptic GluN2B-containng NMDARs limiting intracellular $\mathrm{Ca}^{2+}$ accumulation in the extrasynaptic regions. Synaptic GluN2A-containing NMDARs are kept activated by $\mathrm{HCY}$ that allows intracellular $\mathrm{Ca}^{2+}$ accumulation in post-synaptic regions and presynaptic terminal inducing synaptic $\mathrm{Ca}^{2+}$ oscillations. 
Gladding and Raymond, 2011; Stark and Bazan, 2011). Given the preferential contribution of GluN2A-containing NMDARs to the HCY effects, this amino acid is expected to be much less efficient neurotoxicant, than NMDA. In consistence to achieve the similar levels of apoptosis in primary culture of rat cortical neurons a 24h exposure to HCY was required (Abushik et al., 2014), instead of a 4-h exposure to NMDA (Sibarov et al., 2012). Unlike NMDAinduced excitotoxicity is sensitive to NMDAR inhibitors (Church et al., 1988; Mironova et al., 2007), apoptosis caused by HCY is highly sensitive to the mGluR5 antagonist MTEP (Abushik et al., 2014). The latter suggests that mGluR5 receptors are most important players in triggering HCY excitotoxicity, rather than NMDARs. Based on current observations, we suggest that HCY preferentially increases the synaptic excitability activating the GluN2A-containing NMDARs as well as mGluR5 which can functionally interact with NMDARs at the pre- and postsynaptic compartments (Sylantyev et al., 2013). In contrast to the GluN2A-containing NMDARs, the effects mediated by the GluN2B-containing receptors are expected to be inhibited in the presence of HCY due to essential desensitization (Figure 7). This may have some functional consequences interfering with the development of LTD and affecting the neurotransmitter spillover (Scimemi et al., 2004).

The range of HCY concentrations that activates the GluN2Acontaining receptors $\left(\mathrm{EC}_{50}\right.$ about $\left.9 \mu \mathrm{M}\right)$ corresponds to the normal level of endogenous HCY, which varies from 5 to $15 \mu \mathrm{M}$ in human plasma (Shi et al., 2003). Notably, during hyperhomocysteinemia the concentration of this amino acid can rise up to $200 \mu \mathrm{M}$ (Fritzer-Szekeres et al., 1998) making it likely that HCY can contribute to persistent (due to low desensitization) activation of synaptic type NMDARs. Based on our data, the neurotoxic profiles of NMDA or glutamate (Figure 7A) and HCY (Figure 7B) should be considerably different. In excitotoxicity glutamate activates GluN1/2A and GluN1/2B with similar kinetics and can cause $\mathrm{Ca}^{2+}$ overload

\section{REFERENCES}

Abushik, P. A., Niittykoski, M., Giniatullina, R., Shakirzyanova, A., Bart, G., Fayuk, D., et al. (2014). The role of NMDA and mGluR5 receptors in calcium mobilization and neurotoxicity of homocysteine in trigeminal and cortical neurons and glial cells. J. Neurochem. 129, 264-274. doi: 10.1111/jnc.12615

Antonov, S. M., Gmiro, V. E., and Johnson, J. W. (1998). Binding sites for permeant ions in the channel of NMDA receptors and their effects on channel block. Nat. Neurosci. 1, 451-461. doi: 10.1038/2167

Bolton, A. D., Phillips, M. A., and Constantine-Paton, M. (2013). Homocysteine reduces NMDAR desensitization and differentially modulates peak amplitude of NMDAR currents, depending on GluN2 subunit composition. J. Neurophysiol. 110, 1567-1582. doi: 10.1152/jn.00809.2012

Church, J., Zeman, S., and Lodge, D. (1988). The neuroprotective action of ketamine and MK-801 after transient cerebral ischemia in rats. Anesthesiology 69, 702-709. doi: 10.1097/00000542-198811000-00011

Dalby, N. O., and Mody, I. (2003). Activation of NMDA receptors in rat dentate gyrus granule cells by spontaneous and evoked transmitter release. J. Neurophysiol. 90, 786-797. doi: 10.1152/jn.00118.2003

de Armentia, M. L., and Sah, P. (2003). Development and subunit composition of synaptic NMDA receptors in the amygdala: NR2B synapses in the adult central amygdala. Nat. Neurosci. 23, 6876-6883.

Fritzer-Szekeres, M., Blom, H. J., Boers, G. H., Szekeres, T., and Lubec, B. (1998). Growth promotion by homocysteine but not by homocysteic acid: a role for of extrasynaptic as well as synaptic regions of neurons (Figure 7A). In contrast, in hyperhomocysteinemia HCY activates synaptic GluN1/2A receptors which may cause $\mathrm{Ca}^{2+}$ accumulation in spines and presynaptic terminals (Figure $7 \mathbf{B}$ ). In addition HCY desensitizes mainly extrasynaptic GluN1/2B receptors, thus limiting $\mathrm{Ca}^{2+}$ accumulation in the extrasynaptic regions (Figure 7B). Our findings, therefore, provide molecular mechanisms of HCY neuronal effects and a corroborating evidence for the physiological relevance of endogenous HCY, which may allow understanding the role of this amino acid in modulation of the excitatory neurotransmission and neurotoxicity.

\section{AUTHOR CONTRIBUTIONS}

Experimental work and data acquisition (DS, PA); data analysis and preparation of figures (DS, PA, SA); study design/interpretation and drafting of manuscript (DS, RG, SA); final approval of manuscript (DS, PA, RG, SA).

\section{FUNDING}

The work of DS, PA, and SA was supported by the Russian Science Foundation (grant 16-15-10192). The work of RG was supported by Finnish Academy (grant 277442).

\section{ACKNOWLEDGMENTS}

We thank Dr. J. W. Johnson for careful reading and critical suggestions on the manuscript and for providing NMDAR plasmids. Calcium imaging experiments were performed in the Research Resource Center of the IEPhB RAS.

excessive growth in homocystinuria or proliferation in hyperhomocysteinemia? Biochim. Biophys. Acta 1407, 1-6. doi: 10.1016/S0925-4439(98)00008-8

Ganapathy, P. S., White, R. E., Ha, Y., Bozard, B. R., McNeil, P. L., Caldwell, R. W., et al. (2011). The role of N-methyl-D-aspartate receptor activation in homocysteine-induced death of retinal ganglion cells. Invest. Ophthalmol. Vis. Sci. 52, 5515-5524. doi: 10.1167/iovs.10-6870

Gladding, C. M., and Raymond, L. A. (2011). Mechanisms underlying NMDA receptor synaptic/extrasynaptic distribution and function. Mol. Cell. Neurosci. 48, 308-320. doi: 10.1016/j.mcn.2011.05.001

Han, E. B., and Stevens, C. F. (2009). Development regulates a switch between postand presynaptic strengthening in response to activity deprivation. Proc. Natl. Acad. Sci. U.S.A. 106, 10817-10822. doi: 10.1073/pnas.0903603106

Hardingham, G. E., and Bading, H. (2010). Synaptic versus extrasynaptic NMDA receptor signalling: implications for neurodegenerative disorders. Nat. Rev. Neurosci. 11, 682-696. doi: 10.1038/nrn2911

Kilić, G., Sciancalepore, M., and Cherubini, E. (1992). Single-channel currents of NMDA type activated by L- and D-homocysteic acid in cerebellar granule cells in culture. Neurosci. Lett. 141, 231-235. doi: 10.1016/0304-3940(92)90901-I

Kim, W. K., and Pae, Y. S. (1996). Involvement of N-methyl-D-aspartate receptor and free radical in homocysteine-mediated toxicity on rat cerebellar granule cells in culture. Neurosci. Lett. 216, 117-120. doi: 10.1016/0304-3940(96) 13011-1

Kowa, H., Yasui, K., Takeshima, T., Urakami, K., Sakai, F., and Nakashima, K. (2000). The homozygous C677T mutation in the methylenetetrahydrofolate 
reductase gene is a genetic risk factor for migraine. Am. J. Med. Genet. 96, 762764. doi: 10.1002/1096-8628(20001204)96:6 < 762::AID-AJMG12>3.0.CO;2-X

Kruman, I. I., Kumaravel, T. S., Lohani, A., Pedersen, W. A., Cutler, R. G., Kruman, Y., et al. (2002). Folic acid deficiency and homocysteine impair DNA repair in hippocampal neurons and sensitize them to amyloid toxicity in animal models of Alzheimer's disease. J. Neurosci. 22, 1752-1762.

Kuhn, W., Hummel, T., Woitalla, D., and Muller, T. (2001). Plasma homocysteine and MTHFR C677T genotype in levodopa-treated patients with PD. Neurology 56, 281-282. doi: 10.1212/WNL.56.2.281

Lea, R., Colson, N., Quinlan, S., Macmillan, J., and Griffiths, L. (2009). The effects of vitamin supplementation and MTHFR (C677T) genotype on homocysteinelowering and migraine disability. Pharmacogenet. Genomics 19, 422-428. doi: 10.1097/FPC.0b013e32832af5a3

Legendre, P., Rosenmund, C., and Westbrook, G. L. (1993). Inactivation of NMDA channels in cultured hippocampal neurons by intracellular calcium. J. Neurosci. $13,674-684$

Lester, R. A., and Jahr, C. E. (1992). NMDA channel behavior depends on agonist affinity. J. Neurosci. 12, 635-643.

Lipton, S. A., Kim, W. K., Choi, Y. B., Kumar, S., D’Emilia, D. M., Rayuda, P. V., et al. (1997). Neurotoxicity associated with dual actions of homocysteine at the N-methyl-D-aspartate receptor. Proc. Natl. Acad. Sci. U.S.A. 94, 5923-5928. doi: 10.1073/pnas.94.11.5923

Mironova, E. V., Evstratova, A. A., and Antonov, S. M. (2007). A fluorescence vital assay for the recognition and quantification of excitotoxic cell death by necrosis and apoptosis using confocal microscopy on neurons in culture. J. Neurosci Methods 163, 1-8. doi: 10.1016/j.jneumeth.2007.02.010

Mizuta, I., Katayama, M., Watanabe, M., Mishina, M., and Ishii, K. (1998). Developmental expression of NMDA receptor subunits and the emergence of glutamate neurotoxicity in primary cultures of murine cerebral cortical neurons. Cell. Mol. Life Sci. 54, 721-725. doi: 10.1007/s000180050199

Momiyama, A. (2000). Distinct synaptic and extrasynaptic NMDA receptors identified in dorsal horn neurones of the adult rat spinal cord. J. Physiol. 523, 621-628. doi: 10.1111/j.1469-7793.2000.t01-1-00621.x

Moschiano, F., D’Amico, D., Usai, S., Grazzi, L., Di Stefano, M., Ciusani, E., et al. (2008). Homocysteine plasma levels in patients with migraine with aura. Neurol. Sci. 29, 173-175. doi: 10.1007/s10072-008-0917-2

Oterino, A., Toriello, M., Valle, N., Castillo, J., Alonso-Arranz, A., Bravo, Y., et al. (2010). The relationship between homocysteine and genes of folaterelated enzymes in migraine patients. Headache 50, 99-168. doi: 10.1111/j.15264610.2009.01484.x

Paoletti, P., Bellone, C., and Zhou, Q. (2013). NMDA receptor subunit diversity: impact on receptor properties, synaptic plasticity and disease. Nat. Rev. Neurosci. 14, 383-400. doi: 10.1038/nrn3504

Poddar, R., and Paul, S. (2013). Novel crosstalk between ERK MAPK and p38 MAPK leads to homocysteine-NMDA receptor-mediated neuronal cell death. J. Neurochem. 124, 558-570. doi: 10.1111/jnc. 12102

Provini, L., Ito, S., Ben Ari, Y., and Cherubini, E. (1991). L-Homocysteate preferentially activates $\mathrm{N}$-methyl-D-aspartate receptors to CA1 rat hippocampal neurons. Eur. J. Neurosci. 3, 962-970. doi: 10.1111/j.1460-9568. 1991.tb00032.x

Qian, A., Buller, A. L., and Johnson, J. W. (2005). NR2 subunit dependence of NMDA receptor channel block by external Mg2 $2^{+}$. J. Physiol. 562, 319-331. doi: 10.1113/jphysiol.2004.076737

Sachdev, P. S. (2005). Homocysteine and brain atrophy. Prog. Neuropsychopharmacol. Biol. Psychiatry 29, 1152-1161. doi: 10.1016/ j.pnpbp.2005.06.026
Scimemi, A., Fine, A., Kullmann, D. M., and Rusakov, D. A. (2004). NR2Bcontaining receptors mediate cross talk among hippocampal synapses. J. Neurosci. 24, 4767-4777. doi: 10.1523/JNEUROSCI.0364-04.2004

Shi, Q., Savage, J. E., Hufeisen, S. J., Rauser, L., Grajkowska, E., Ernsberger, P., et al. (2003). L-homocysteine sulfinic acid and other acidic homocysteine derivatives are potent and selective metabotropic glutamate receptor agonists. J. Pharmacol. Exp. Ther. 305, 131-142. doi: 10.1124/jpet.102.047092

Sibarov, D. A., Abushik, P. A., Poguzhelskaya, E. E., Bolshakov, K. V., and Antonov, S. M. (2015). Inhibition of plasma membrane $\mathrm{Na} / \mathrm{Ca}$-exchanger by KB-R7943 or lithium reveals its role in Ca-dependent NMDAR inactivation. J. Pharmacol. Exp. Ther. 355, 484-495. doi: 10.1124/jpet.115.227173

Sibarov, D. A., Bolshakov, A. E., Abushik, P. A., Krivoi, I. I., and Antonov, S. M. (2012). $\mathrm{Na}^{+}, \mathrm{K}^{+}$-ATPase functionally interacts with the plasma membrane $\mathrm{Na}^{+}, \mathrm{Ca}_{2}{ }^{+}$exchanger to prevent $\mathrm{Ca}_{2}{ }^{+}$overload and neuronal apoptosis in excitotoxic stress. J. Pharmacol. Exp. Ther. 343, 596-607. doi: 10.1124/jpet.112.198341

Stark, D. T., and Bazan, N. G. (2011). Synaptic and extrasynaptic NMDA receptors differentially modulate neuronal cyclooxygenase-2 function, lipid peroxidation, and neuroprotection. J. Neurosci. 31, 13710-13721. doi: 10.1523/JNEUROSCI.3544-11.2011

Steigerwald, F., Schulz, T. W., Schenker, L. T., Kennedy, M. B., Seeburg, P. H., and Kohr, G. (2000). C-terminal truncation of NR2A subunits impairs synaptic but not extrasynaptic localization of NMDA receptors. J. Neurosci. 20, 4573-4581.

Sylantyev, S., Savtchenko, L. P., Ermolyuk, Y., Michaluk, P., and Rusakov, D. A. (2013). Spike-driven glutamate electrodiffusion triggers synaptic potentiation via a homer-dependent mGluR-NMDAR link. Neuron 77, 528-541. doi: 10.1016/j.neuron.2012.11.026

Tovar, K. R., and Westbrook, G. L. (1999). The incorporation of NMDA receptors with a distinct subunit composition at nascent hippocampal synapses in vitro. J. Neurosci. 19, 4180-4188.

Traynelis, S. F., Wollmuth, L. P., McBain, C. J., Menniti, F. S., Vance, K. M., Ogden, K. K., et al. (2010). Glutamate receptor ion channels: structure, regulation, and function. Pharmacol. Rev. 62, 405-496. doi: 10.1124/pr.109.002451

Williams, K. (1993). Ifenprodil discriminates subtypes of the N-methyl-Daspartate receptor: selectivity and mechanisms at recombinant heteromeric receptors. Mol. Pharmacol. 44, 851-859.

Zhang, S., Ehlers, M. D., Bernhardt, J. P., Su, C. T., and Huganir, R. L. (1998). Calmodulin mediates calcium-dependent inactivation of $\mathrm{N}$-methyl-D-aspartate receptors. Neuron 12, 443-453. doi: 10.1016/S0896-6273(00)80553-X

Zhong, J., Russell, S. L., Pritchett, D. B., Molinoff, P. B., and Williams, K. (1994). Expression of mRNAs encoding subunits of the N-methyl-D-aspartate receptor in cultured cortical neurons. Mol. Pharmacol. 45, 846-853.

Zoccolella, S., Bendotti, C., Beghi, E., and Logroscino, G. (2010). Homocysteine levels and amyotrophic lateral sclerosis: a possible link. Amyotroph. Lateral Scler. 11, 140-147. doi: 10.3109/17482960902919360

Conflict of Interest Statement: The authors declare that the research was conducted in the absence of any commercial or financial relationships that could be construed as a potential conflict of interest.

Copyright $\odot 2016$ Sibarov, Abushik, Giniatullin and Antonov. This is an open-access article distributed under the terms of the Creative Commons Attribution License (CC BY). The use, distribution or reproduction in other forums is permitted, provided the original author(s) or licensor are credited and that the original publication in this journal is cited, in accordance with accepted academic practice. No use, distribution or reproduction is permitted which does not comply with these terms. 